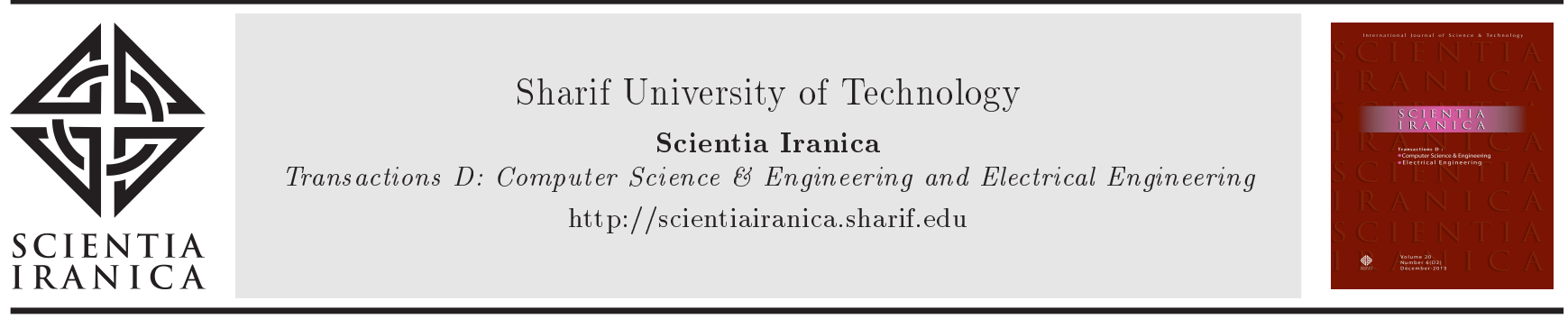

Research Note

\title{
Technical and economic considerations for the application of permanent magnet brushless motors in evaporative water coolers
}

\author{
A. Halvaei Niasar ${ }^{a, *}$, H. Nik Khah ${ }^{\mathrm{a}}$, and F. Eshrat Abadi ${ }^{\mathrm{c}}$ \\ a. Department of Electrical \& Computer Engineering, University of Kashan, Kashan, P.O. Box 8731753153, Iran. \\ b. Arman Energy Company, Block \# 287, South Taavon Blvd., Toos Industrial Town, Mashhad, Iran.
}

Received 12 September 2018; received in revised form 17 October 2018; accepted 17 November 2018

\section{KEYWORDS \\ Energy efficiency; \\ Electric drive; \\ Energy saving; \\ Evaporative cooler; \\ Power quality; \\ Permanent magnet \\ brushless motor.}

\begin{abstract}
Evaporative coolers are used in hot and dry regions of many countries, especially in Iran, due to their low cost. Conventional evaporative coolers use Single-Phase Induction Motors (SPIMs). However, the benefits of these motors are quite inconsiderable, which has led industrial parties to consider replacing them with highly efficient electrical motors. In this paper, the details of using brushless motors in the application of evaporative cooler are presented. A $1 / 2 \mathrm{hp}$ brushless motor and a drive are designed and built. This motor-drive is tested by a dynamometer and standard testing equipment. Further, for the approval of this motor-drive, a $5000 \mathrm{~m}^{3} / \mathrm{h}$ direct evaporative water cooler equipped with this motor is examined under the airflow rate test in the reference laboratory. The results obtained in both tests are compared with the test results of a typical SPIM. The results verify the increase of at least $60 \%$ for energy efficiency compared to evaporative coolers equipped with SPIM. Moreover, a new control scheme based on power control instead of speed control is proposed to stabilize the outlet airflow rate. The results indicate that the application of brushless motors in this application can offer considerable energy saving and help protect the environment.

(C) 2020 Sharif University of Technology. All rights reserved.
\end{abstract}

\section{Introduction}

The increased energy consumption in the world, including Iran, and the exceedance of the peak production in warm seasons have created many problems for consumers, power distribution companies, and power plants. This issue has led to customers' disappointment, especially in the tropical regions of the country, and created public discontent at the community level.

*. Corresponding author. Tel.: +983155913465 E-mail addresses: halvaei@kashanu.ac.ir (A. Halvaei Niasar); nikkhah72@yahoo.com (H. Nik Khah); fariborz_esh@yahoo.com (F.Eshrat Abadi)

doi: $10.24200 /$ sci.2018.51729.2334
Moreover, the installation of new power plants to respond to the peak of load is neither economically nor ecologically justifiable. To solve these problems, one of the issues that concerns electricity companies and the government the most is the reduction of energy consumption by increasing the efficiency of electrical equipment $[1,2]$.

One of the major consumers of electric power in the entire world is electrical motors, and the related statistics indicate that more than $50 \%$ of generated electrical energy is consumed in motors. This percentage is still higher in the residential and commercial sectors, which may pass by more than $70 \%$ of energy. It is wise to increase energy consumption efficiency firstly in applications that have the highest and longest hours of daily usage. Electric motors used in refrigerator com- 


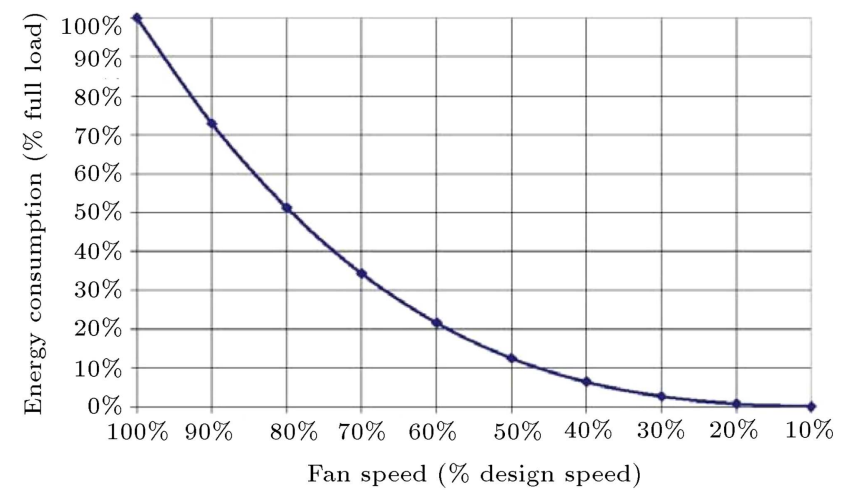

Figure 1. Energy consumption versus the shaft speed of a blower [6].

pressors, air conditioners, blowers, washing machines, and dishwashers are among those consumers whose manufacturers have made great efforts to improve the performance of their motors or substitute them with highly efficient motors [3].

The use of variable speed drives to feed electric motors in industrial applications is one of the solutions adopted almost entirely in the industry and utility applications. Equipping industrial air-conditioning motors (HVACs) with electrical drives has been considered in most industries [4]. Since the power consumption of an air blower is proportional to its third power, the use of variable speed drives and the change in speed to achieve proper air conditioning can significantly reduce energy consumption [5]. Figure 1 shows the energy curve of a blower in terms of speed. It can be seen that, in $80 \%$ and $60 \%$ of the rated speeds, energy consumption is reduced by about $50 \%$ and $80 \%$, respectively [6]. However, in applications with low power consumption, especially domestic and commercial usages, in which Single-Phase Induction Motors (SPIMs) are often used, the use of electrical drive due to inherent low efficiency and inadequate benefits of SPIMs may not have a significant effect on energy saving; therefore, the addition of drive increases the costs, which can greatly reduce the success rate in commercial sales. Therefore, the first step in these applications is to increase the efficiency of electric motors by improving the design or the use of new high-performance motors such as Permanent Magnet Brushless (PMBL) motors $[7,8]$.

In Iran, due to the warm and dry climate of most regions of the country, electric motors used in evaporative coolers are the most widely used electric consumers. The country's official statistics show that there are 17 million evaporative coolers that work more than half of year. Considering the power rate of $400 \mathrm{~W}$ consumed per each evaporative cooler and the efficiency rate of $70 \%$ for power transfer from power plants to the home use, about $10 \mathrm{GW}$ of generated power is consumed by evaporative coolers all over the country. It is a very significant number that equals about $20 \%$ of the maximum generated power in Iran. The substitution of SPIM by high-efficiency motors in an evaporative cooler generates at least $30 \%$ saving per each motor. It results in savings of about $3 \mathrm{GW}$ as the rated power of three great power plants $[9,10]$.

One of the motors that can be used as a substitute for SPIM in conventional evaporative coolers is PMBL motors $[11,12]$ that generally enjoy an efficiency rate of over $85 \%$. Considering that the drive of PMBL motor enjoys an efficiency rate of more than $95 \%$, the overall efficiency of PMBL motor drive with respect to power grid's capacity can easily exceed $80 \%$. Comparisons of these values and similar values for SPIMs confirm the increase rate of at least $30 \%$ in efficiency. Along with a significant decrease in electric power consumption by brushless motors, there are other notable features such as variable speed capability (rather than two speeds for traditional SPIM of coolers), remote control ability, and integration with building management system, although the issues of power quality, reactive power, and voltage's Total Harmonics Distortion (THD) are also fully considered to meet the drive's standard design [13].

The rest of this paper is organized as follows: Section 2 describes the developed national standards and technical requirements for PMBL used in evaporative coolers. Section 3 presents the results of the fabrication and testing of the PMBL in accordance with the national standards. Section 4 gives the routine test results of the manufactured motor drive by using a dynamometer. Section 5 provides the results of the airflow test of the cooler based on PMBL motor drive in the reference laboratory. Section 6 presents the speed control and power control methods and compares their experimental results. Section 7 discusses the technical and economic considerations of this replacement. Section 8 is dedicated to the results of this paper and offers more practical suggestions.

\section{Requirements for brushless motors used in evaporative cooler}

There have not been any international or national standards for brushless motors in the case of evaporative coolers. Therefore, considering the existence of the large market of these motors and offering guidance to the manufacturers in the form of a united procedure, the requirements for the brushless motor used in the evaporative cooler application are determined by the Iranian National Standardization Organization (INSO). In this way, a new national standard INSO 3772-30-1-3:2017, entitled "Rotating electrical machines-Specification and Criteria for Energy Consumption and Energy Labeling Instruction of BLDC motors", has been developed [13]. 
Most of the evaporative coolers in the market are of three main categories with airflow rates of 3500 , 5000 , and $7000 \mathrm{~m}^{3} / \mathrm{h}$. With respect to the outlet power of the corresponding centrifuge blowers of these coolers, the SPIMs used in these coolers have the rated power of $1 / 3,1 / 2$, and $3 / 4$ horsepower $(h p)$. Thus, the output power of the brushless motors used in these three coolers is chosen exactly the same as the three mentioned SPIMs. Moreover, owing to the considerations associated with the design of available cooler blowers, the blower speed of coolers equipped with the brushless motor is chosen exactly the same as the blower speed of the conventional coolers. Moreover, the ratio of the blower's pulley diameter to motor's pulley diameter is selected equal to the corresponding values in the conventional evaporative coolers. Table 1 lists the functional requirements for and specifications of the $1 / 2 \mathrm{hp}$ brushless motor used in the $5000 \mathrm{~m}^{3} / \mathrm{h}$ evaporative cooler. For coolers of $3500 \mathrm{~m}^{3} / \mathrm{h}$ and $7000 \mathrm{~m}^{3} / \mathrm{h}$, similar specifications have been developed. In addition to the functional characteristics listed in Table 1, they should meet other requirements. For example, the number of wires between the control key and the drive must be up to 4 wires. The length of the cable between the control key and the drive must meet at least a distance of 25 meters. Standard protections such as overvoltage (OV), undervoltage (UV), temperature protection (TP), short circuit protection (SC), and open circuit (OC) must also be designed in the drive. Other motor design codes such as electrical insulation code (IVIC), construction code (IM), cooling code (IC), and thermal class code must be determined by the manufacturer, too. Furthermore, the designed motor and drive must pass the EMC test according to the relevant standard, and the life cycle of the motor and drive must also be specified by the manufacturer.

\section{Brushless motor and drive system}

Today, the use of brushless motors in a wide range of household applications, such as washing machines, refrigerator compressors, dishwashers, air conditioners, and HVAC systems, will save considerable energy and improve performance [14]. With these results, equipping evaporative coolers that are estimated to be 17 million in number as the largest consumer of electrical power in the country is completely justifiable. Another important point is that the life cycle of SPIMs for evaporative coolers is short (at most, 3 years). After reaching the end of their life cycle, these motors are either thrown away or improperly repaired, causing

Table 1. Requirements and performance characteristics of the $1 / 2 \mathrm{hp}$ brushless motor for use in a $5000 \mathrm{~m}^{3} / \mathrm{h}$ evaporative water cooler.

\begin{tabular}{|c|c|c|}
\hline Parameter & Value & Comment \\
\hline Motor output power & $375 \mathrm{~W}$ & At high speed (rated speed) \\
\hline Low speed of blower & $300 \mathrm{rpm}$ & $\pm 10 \mathrm{rpm}$ \\
\hline High speed of blower & $450 \mathrm{rpm}$ & $\pm 10 \mathrm{rpm}$ \\
\hline Low speed of motor & $950 \mathrm{rpm}$ & Motor and blower pulleys diameters \\
\hline High speed of motor & $1450 \mathrm{rpm}$ & are $70 \mathrm{~mm}$ and $256 \mathrm{~mm}$ \\
\hline Efficiency at low speed & $66.3 \%$ & At input of drive \\
\hline Efficiency at high speed & $81.1 \%$ & At input of drive \\
\hline Efficiency at half of rated speed & $61.9 \%$ & According to INSO 3772-30-1-3 \\
\hline Input voltage of drive & $220 \mathrm{~V}$ & Working between $175 \mathrm{~V}-250 \mathrm{~V}$ \\
\hline Power factor of drive & $>0.95$ & Both high/low speeds \\
\hline Common mode current & $<40 \mathrm{~mA}$ & At output of drive \\
\hline Startup time & $<5 \mathrm{sec}$ & In sensor mode \\
\hline Speed ripple & $<1 \% \omega_{\text {rated }}$ & - \\
\hline \multirow{3}{*}{$\begin{array}{l}\text { Total harmonic distortion of } \\
\text { current (based on INSO 72603-2) }\end{array}$} & $1.9 \mathrm{~A}$ & 3rd harmonic \\
\hline & $1 \mathrm{~A}$ & 4th harmonic \\
\hline & $0.55 \mathrm{~A}$ & 7th harmonic \\
\hline Acoustic noise & $<55 \mathrm{~dB}$ & - \\
\hline Mechanical vibration & $<1.6 \mathrm{~mm} / \mathrm{S}^{2}$ & - \\
\hline IP code of drive & 55 & - \\
\hline IP code of motor & 22 & - \\
\hline
\end{tabular}



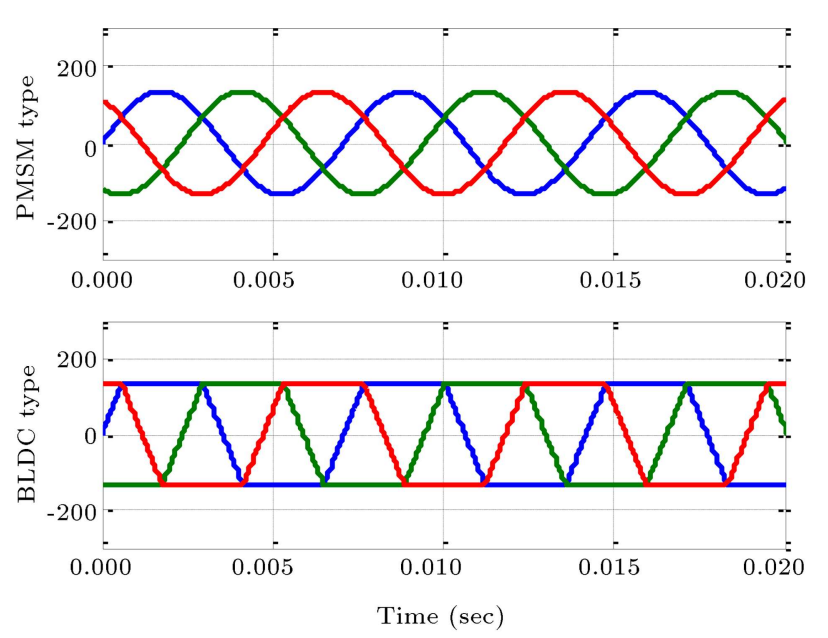

Figure 2. Various back-EMF voltages of permanent magnet brushless motors.

higher energy consumption, even greater than their initial rated value. The purpose of this research is to design and manufacture a suitable brushless motor and drive to be applied to the evaporative cooler while meeting all of the functional requirements.

\subsection{Brushless motor}

PMBL motors are mainly divided into two main groups: brushless AC (PMSM) and brushless DC (BLDC) motors [15]. As shown in Figure 2, in the PMSM type, the induced phase back-EMF voltage waveform is sinusoidal, whereas the BLDC type has the trapezoidal phase back-EMF voltage with flat portion over a range of 120 degrees, although there are some other PMBL motors whose phase back-EMF voltages are neither ideally trapezoidal nor sinusoidal, which have their own control considerations. This difference is due to the pole arrangement on the rotor and stator winding distribution that is sinusoidally distributed in PMSM, whereas it is distributed in a uniform or centralized fashion in BLDC motor [16]. In terms of economic considerations and production constraints, making a stator core with a centralized distribution is much simpler. In addition, the copper conductor winding is even easier and cheaper in centralized stator slots. The rotor of both types of motors includes one or more pairs of permanent magnets, which can be used in the application of evaporative coolers as surfacemounted PM rotors due to the low rotational speed of the motor.

The designed brushless motor in this research is an inner rotor with 8 poles. Figure 3 shows the stator core and the stator winding of the three-phase brushless motor. The stator is connected like a star and consists of 12 slots with each phase consisting of 4 coils and each coil including 45 turns with a copper conductor of $0.6 \mathrm{~mm}^{2}$. The insulator used in the stator is a single piece that makes the assembly and production work easily. Moreover, the rotor of the manufactured brushless motor with ferrite PM is shown in Figure 3(b). The results of the finite element analysis, as well as the motor generator test, indicate that the induced back-EMF voltage of the designed motor has a non-sinusoidal shape.

\subsection{Brushless motor control strategy}

The difference of back-EMF voltage waveform in brushless motors is the reason why the employed control methods are so different. To develop a constant instantaneous torque for PMSMs, vector-based control such as field-oriented control or direct torque control in two-axis reference frames is usually used. However, for BLDCMs, the application of vector-based methods is not common, and their utilization may lead to lots of torque ripple. Therefore, simple quasi-square (six-step) current methods are employed. The main advantages of six-step current methods for BLDCMs are hardware/software simplicity and ease of implementation [17].

In controlling the PMSM motors, it is necessary to determine the instantaneous value of the rotor position, and, for this purpose, a costly resolver or shaft encoders or state estimators are usually used in a sensorless approach. However, in controlling the BLDC motors, only knowing six rotor positions that are in accordance with the commutation instants is sufficient and, for this purpose, three low-cost hall-effect sensors

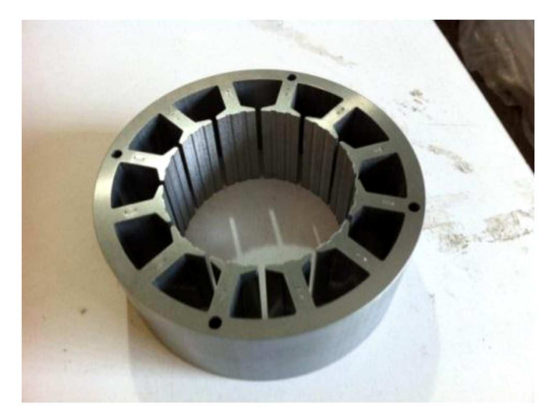

(a)

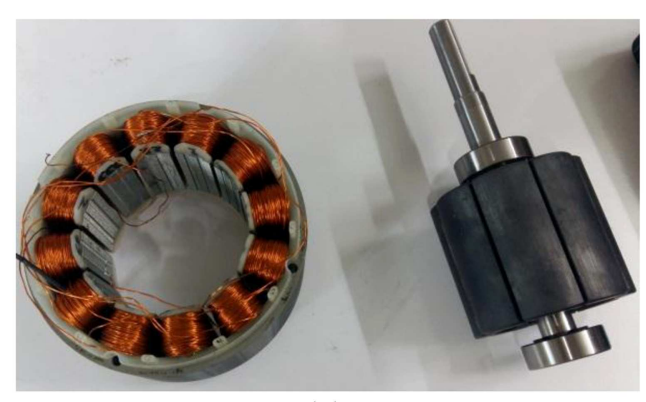

(b)

Figure 3. Main parts of the designed brushless motor for evaporative cooler: (a) Stator core of designed brushless motor and (b) stator winding and permanent magnet rotor. 


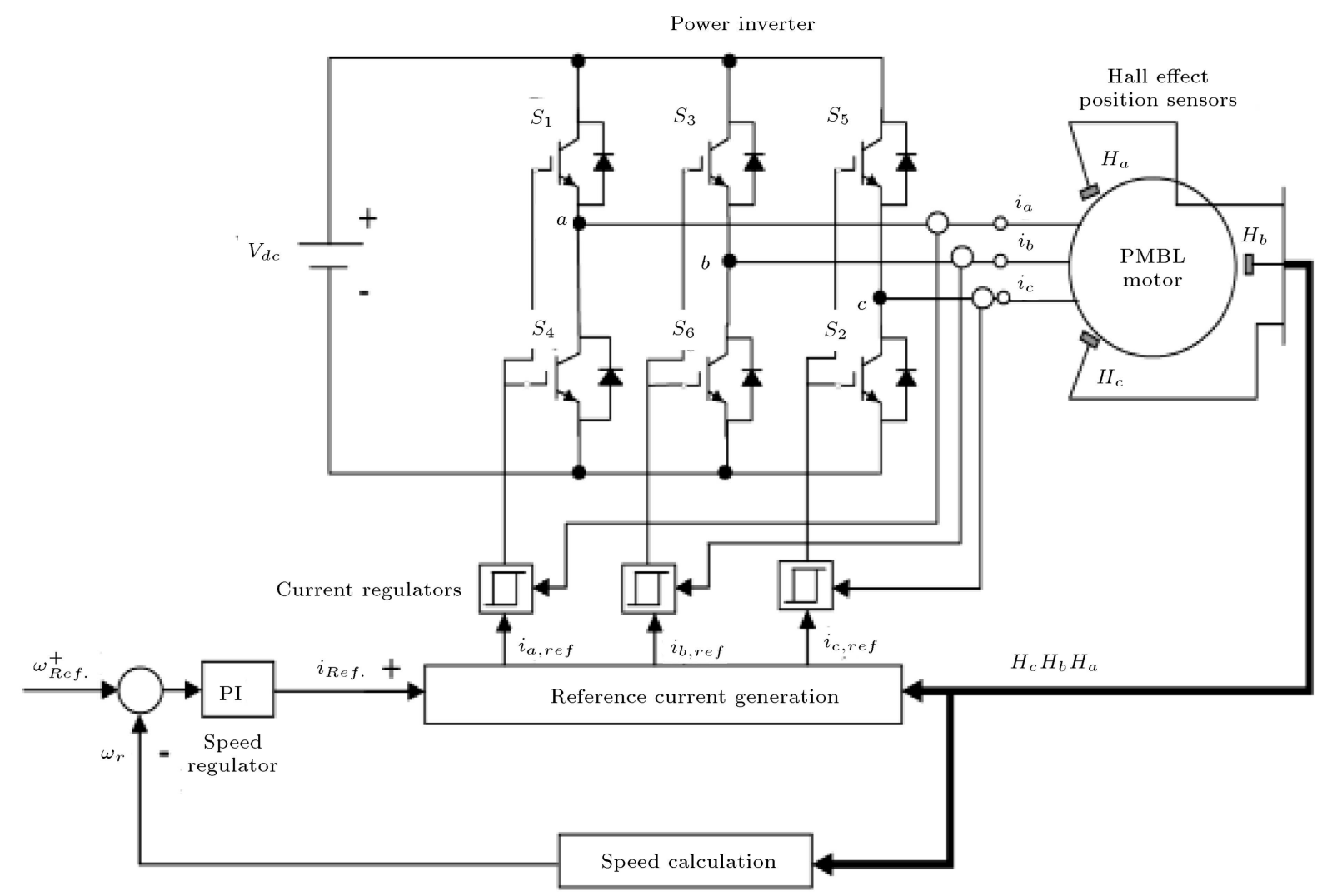

Figure 4. Conventional control system of the brushless motor used for an evaporative cooler.

are used. In the case of PMBL motors, where the induced back-EMF voltage is neither sinusoidal nor the ideally trapezoidal, the control method used is dependent on the application. If the very smooth torque is required, special control methods such as Selective torque Harmonic Elimination (SHE) method or improved vector control technique should be used. Otherwise, both vector control and the six-step current control method can be used [18].

In the application of the evaporative cooler, according to Table 1, the standard requirement for the mechanical vibration and noise levels is, respectively, $1.6 \mathrm{~mm} / \mathrm{s}^{2}$ and $55 \mathrm{~dB}$, which is not so rigorous. Therefore, for the simplicity of the drive structure, the six-step current control method is employed. Of course, to improve the quality of the torque and protect the current of the phases, three current sensors have been used and, thus, instead of regulation of the dc link current, the independent three-phase current regulation is used. Figure 4 shows the block diagram of the employed control system. The manufactured motor has been tested according to IEC 60034-17 and IEC 60034-14. The amount of measured acoustic noise and mechanical vibration are $1.4 \mathrm{~mm} / \mathrm{s}^{2}$ and $40 \mathrm{~dB}$, which are within the permitted range and the standard requirement. Therefore, the use of independent control of the phase currents with the six-step shape is economical and meets the standard requirements.

\subsection{Brushless motor drive hardware}

The designed drive of the brushless motor includes two separate boards. Figure 5(a) shows the inverter and control embedded into a motor shell and includes an inverter, switch drivers, current sensors, and a microcontroller. Another board, as shown in Figure $5(\mathrm{~b})$, is separate from the motor shell and includes Power Factor Correction (PFC) circuit based on boost converter, input Electromagnetic interference (EMI) filter, and user interface.

\section{Routine test results of the manufactured brushless motor}

In order to validate the design and confirm the performance of motor-drive assembly, it has been tested in the National Standard Laboratory in different conditions. The hysteresis-type dynamometer shown in Figure 6 is used to measure the motor-drive efficiency. This system measures the load torque, motor's speed, and the absorbed power from the drive. Measurements are performed according to INSO 3772-30-1-3 standard. The input power quality is also measured by a power analyzer. To calculate of the efficiency, the direct 


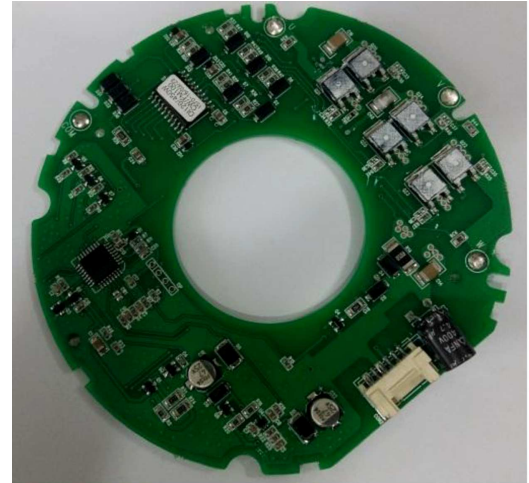

(a)

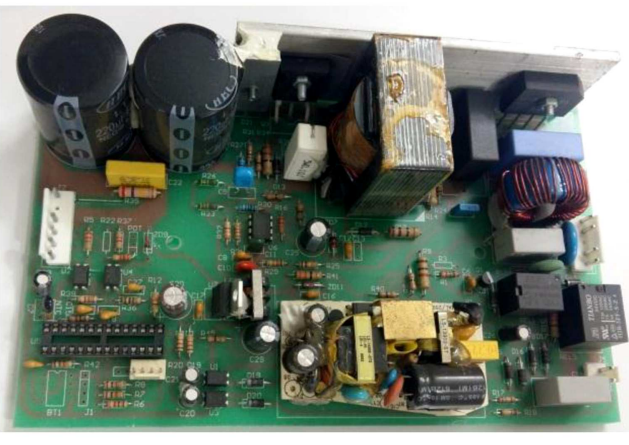

(b)

Figure 5. Manufactured drive of the brushless motor for an evaporative cooler: (a) Inverter and controller board of the drive and (b) Power Factor Corrector (PFC) and interface board.

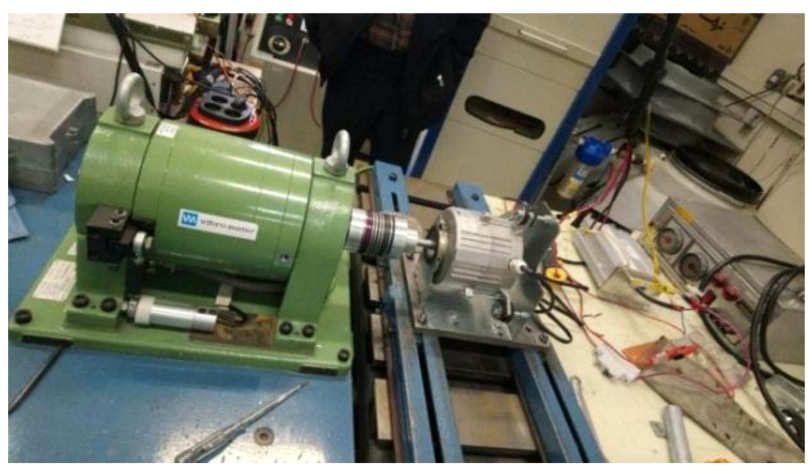

Figure 6. Hysteresis-type dynamometer for efficiency test of brushless motor.

relation of the output power to the input power is used as follows:

$$
\eta=\frac{P_{\text {out }}}{P_{\text {in }}}=\frac{T_{\text {out }} \times \omega_{m}}{V_{l} I_{l} \cos \varphi}
$$

where $\omega_{m}$ denotes the speed of the motor, $T_{\text {out }}$ is the torque on the shaft, which is easily measured by an accurate torque transducer of the dynamometer equipment, and $P_{\text {in }}$ denotes the input power to the drive, which is equal to the main harmonic power of the voltage and current due to the elimination of the input current harmonic by the filter.

To verify the performance of the motor-drive at blower's speeds of $450 \mathrm{rpm}$ (high speed) and $300 \mathrm{rpm}$ (low speed), two types of tests are carried out. In the first test, called the duty test, at a constant speed, the load torque on the shaft is set to the rated torque at a given speed; the motor and drive input/output quantities (including the efficiency, current, power factor, etc.) are measured. In the second test, called the curve test, at a constant speed, the load torque is changed from zero to the nominal value continuously with a certain slope, and the motor and drive output quantities are measured. It should be noted that, due to the design and the ratio of 256/70 for the blower's pulley diameter to motor's pulley diameter, the high and low speeds of the motor will be $1450 / 950 \mathrm{rpm}$ and $950 \mathrm{rpm}$, respectively. The results of both tests are presented separately as follows.

\subsection{Duty test at a high speed of 1450 rpm and a rated torque of $2.5 \mathrm{~N} . \mathrm{m}$}

In this test, at a rated speed $1450 \mathrm{rpm}$, the rated torque of 2.5 N.m is applied to the brushless motor with the power of $375 \mathrm{~W}$ (or $0.5 \mathrm{hp}$ ). For this purpose, the load torque is increased from zero to a rated value in 15 seconds and, then, is kept for 10 minutes in this condition. The sampling frequency of the measuring system is $200 \mathrm{mSec}$. The test results are shown in Figure 7. As shown, the line voltage or input voltage of the drive is set to $220 \mathrm{~V}$, and the load torque applied to the shaft during the test has been kept constant at 2.5 N.m. The drive takes input current $2.5 \mathrm{~A}$, and the motor is running at a speed rate of $1443 \mathrm{rpm}$, which is very close to the reference value of $1450 \mathrm{rpm}$; this error is negligible. The input and output power of the motor are respectively $433 \mathrm{~W}$ and $375 \mathrm{~W}$, resulting in an overall efficiency rate of about $85 \%$, which is a very high value for this household application. This value can be better understood by comparing it with the efficiency of the conventional $1 / 2 \mathrm{hp}$ SPIM, which is at most $50 \%$. For this purpose, a typical $1 / 2 \mathrm{hp}$ SPIM has been tested in the same working condition. The test results at a speed rate of $1437 \mathrm{rpm}$ are shown in Figure 8. It is observed that the SPIM takes 781 $\mathrm{W}$ from the power grid and converts only $372 \mathrm{~W}$ for the load that results in an efficiency rate of $48.3 \%$. In other words, more than half of the absorbed power from the grid is lost. The input current of the SPIM is 3.6 A, which is $50 \%$ more than the current $2.5 \mathrm{~A}$ of the brushless motor. Therefore, the replacement of SPIM with an efficiency rate of $48.3 \%$ by a brushless motor with an efficiency rate of $84.2 \%$ increases the efficiency by about $75 \%$, which is a significant improvement. This improvement, as will be shown below, will be made at a low speed rate of $950 \mathrm{rpm}$. 

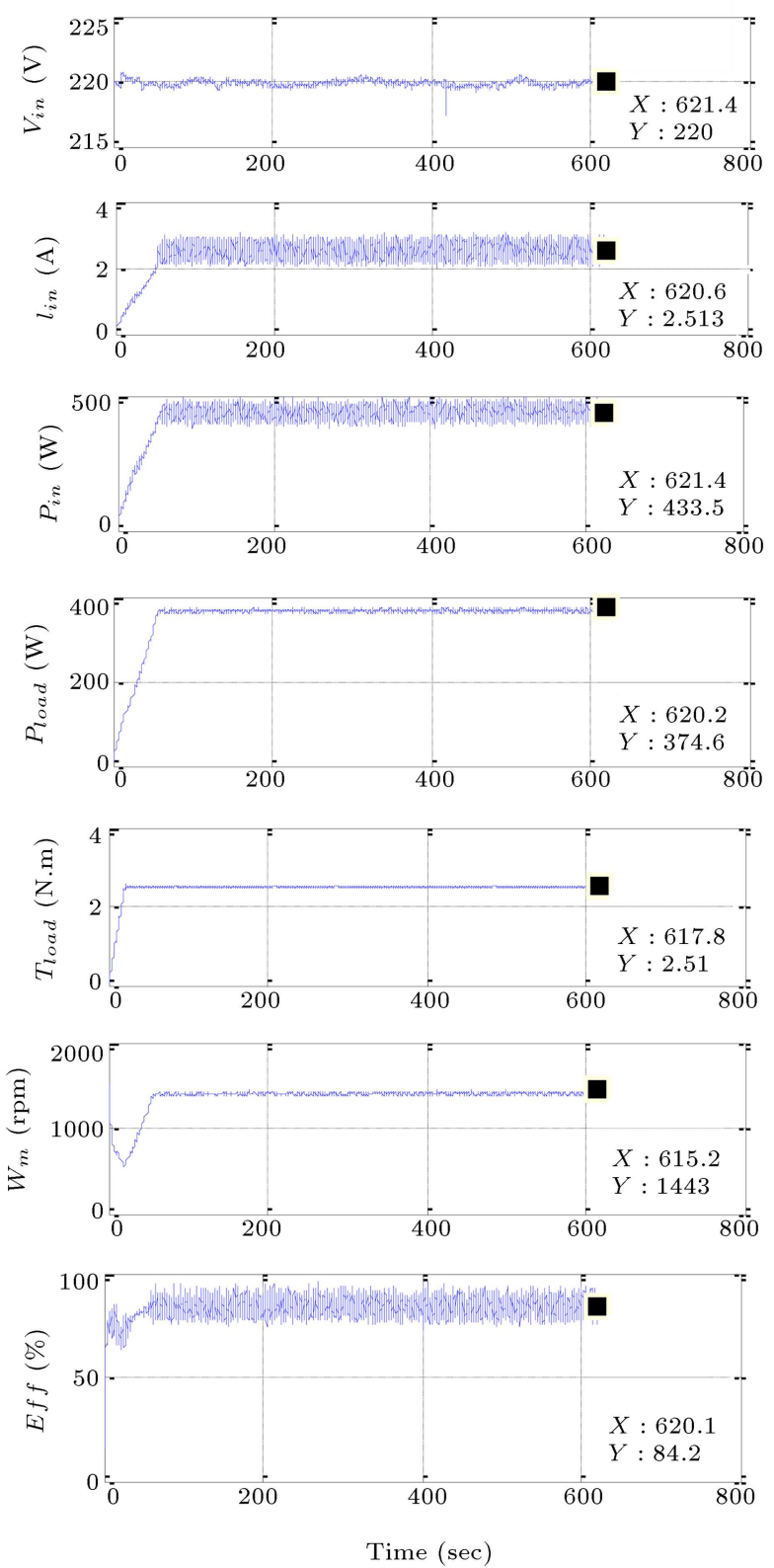

Figure 7. Duty test results of the $1 / 2 \mathrm{hp}$ brushless motor of a 5000 evaporative cooler at a high speed rate of 1450 rpm under rated torque of 2.5 N.m.

\subsection{Duty test at a low speed rate of $950 \mathrm{rpm}$ and a rated torque of 1.25 N.m}

At first, the method for calculating the load torque at a low speed rate is stated. As already mentioned, the high and low speeds of the brushless motor are considered the same as those of the SPIM (1450/950 rpm), in which the low speed of SPIM is $2 / 3$ of its high speed. Moreover, according to the characteristics of the centrifugal blower of the evaporative cooler, the output power of the blower is approximately proportional to cubic of the blower's speed. Hence, the blower power at a lower speed rate is about $1 / 3$ of the power at a high speed. Therefore, with respect to a ratio of $2 / 3$
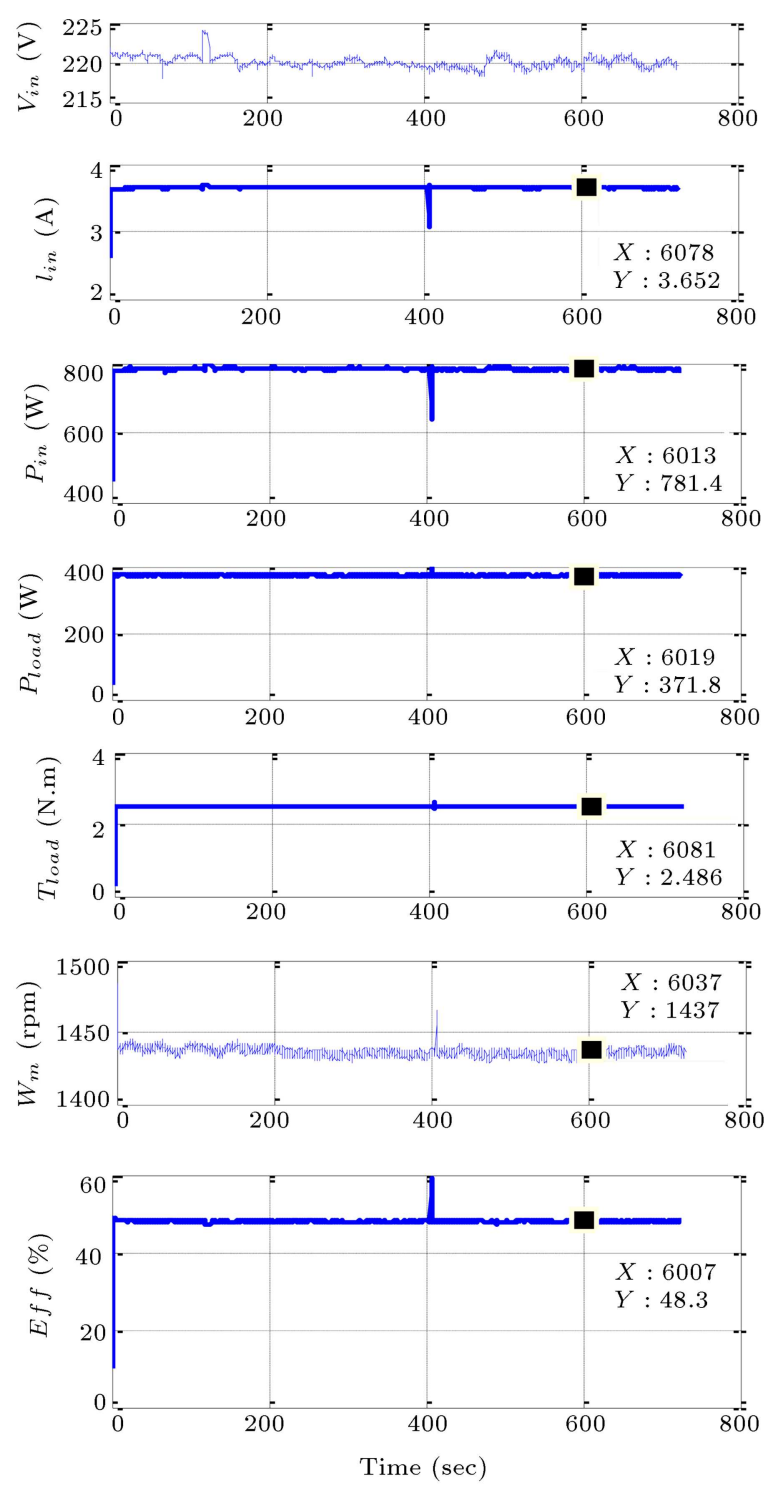

Figure 8. Duty test results of the $1 / 2 \mathrm{hp}$ single-phase induction motor of a 5000 evaporative cooler at a high speed rate of $1450 \mathrm{rpm}$ under rated torque of 2.5 N.m.

between low to high speeds, the load torque at a lower speed rate is about $1 / 2$ of the load torque at a higher speed rate or 1.25 N.m.

The test results at a speed rate of $950 \mathrm{rpm}$ under the load torque of 1.25 N.m are shown in Figure 9. The input voltage of drive is kept on $220 \mathrm{~V}$, and the load torque applied to the shaft during the test is set to $1.25 \mathrm{~N} . \mathrm{m}$. The drive takes input current $0.69 \mathrm{~A}$, and the motor is running at a speed rate of $950 \mathrm{rpm}$, which is exactly the same as the reference speed of the drive. The input and output power of the motor are respectively $151 \mathrm{~W}$ and $120 \mathrm{~W}$, resulting in an overall efficiency rate of about $83.7 \%$. If this efficiency is compared with the conventional $1 / 2 \mathrm{hp}$ SPIMs with efficiency between $30 \% \sim 40 \%$, the advantage of the brushless motor becomes clear. For 

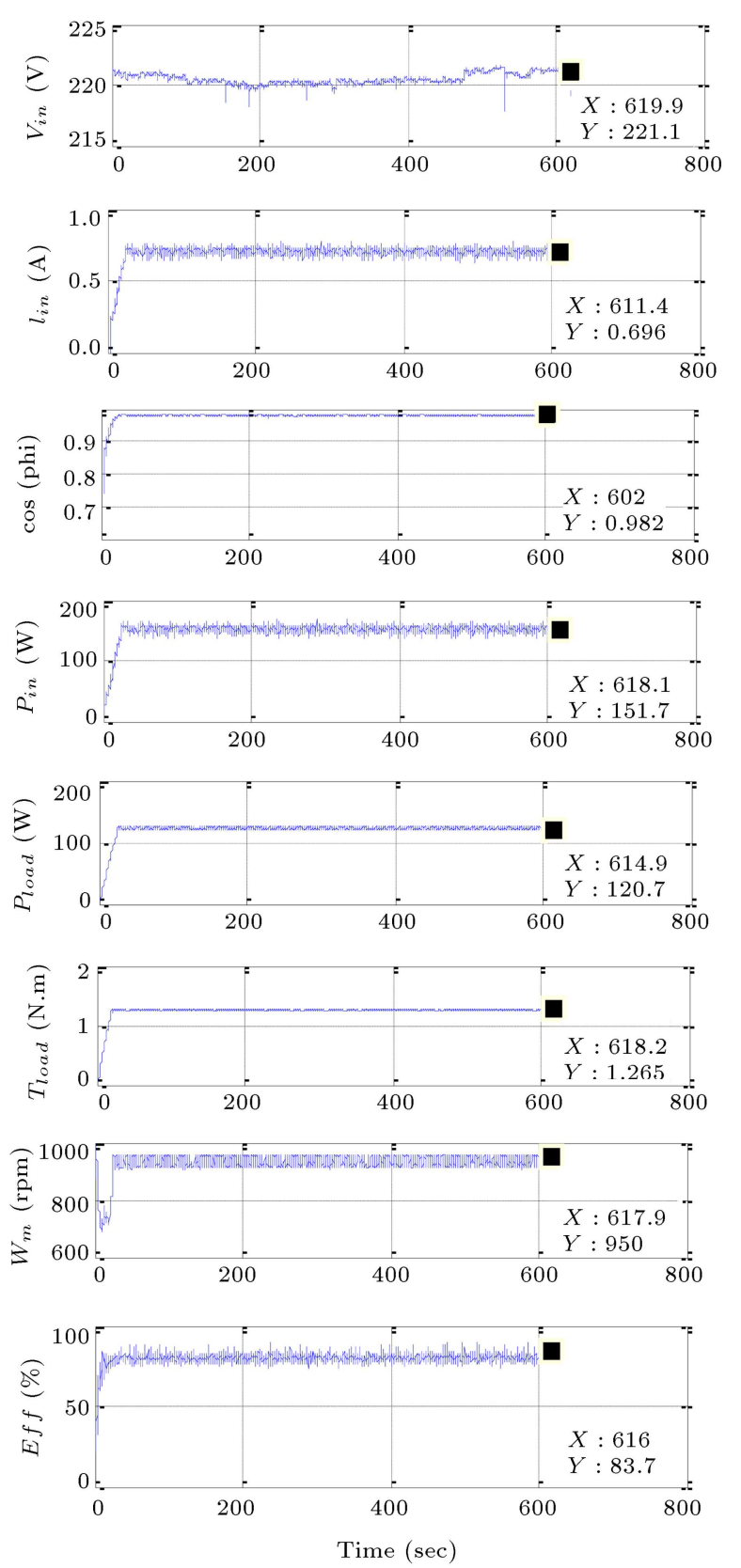

Figure 9. Duty test results of the $1 / 2 \mathrm{hp}$ brushless motor of a 5000 evaporative cooler at a low speed rate of 950 rpm under rated torque of 1.25 N.m.

this purpose, the same SPIM is tested again in a lowspeed condition, and the results of this experiment are shown in Figure 10. The results indicate that the SPIM receives $320 \mathrm{~W}$ from the power grid and outputs only $120 \mathrm{~W}$ on the shaft, leading to an efficiency rate of $37.6 \%$ for the SPIM; it is implied that the motor wastes about $2 / 3$ of absorbed energy. Thus, through the replacement of SPIM with an efficiency rate of $37.6 \%$ by a brushless motor with an efficiency rate of $83.7 \%$, the efficiency increases by about $100 \%$.

Given that the $5000 \mathrm{~m}^{3} / \mathrm{h}$ type evaporative coolers are mostly used rather than 3500 and $7000 \mathrm{~m}^{3} / \mathrm{h}$
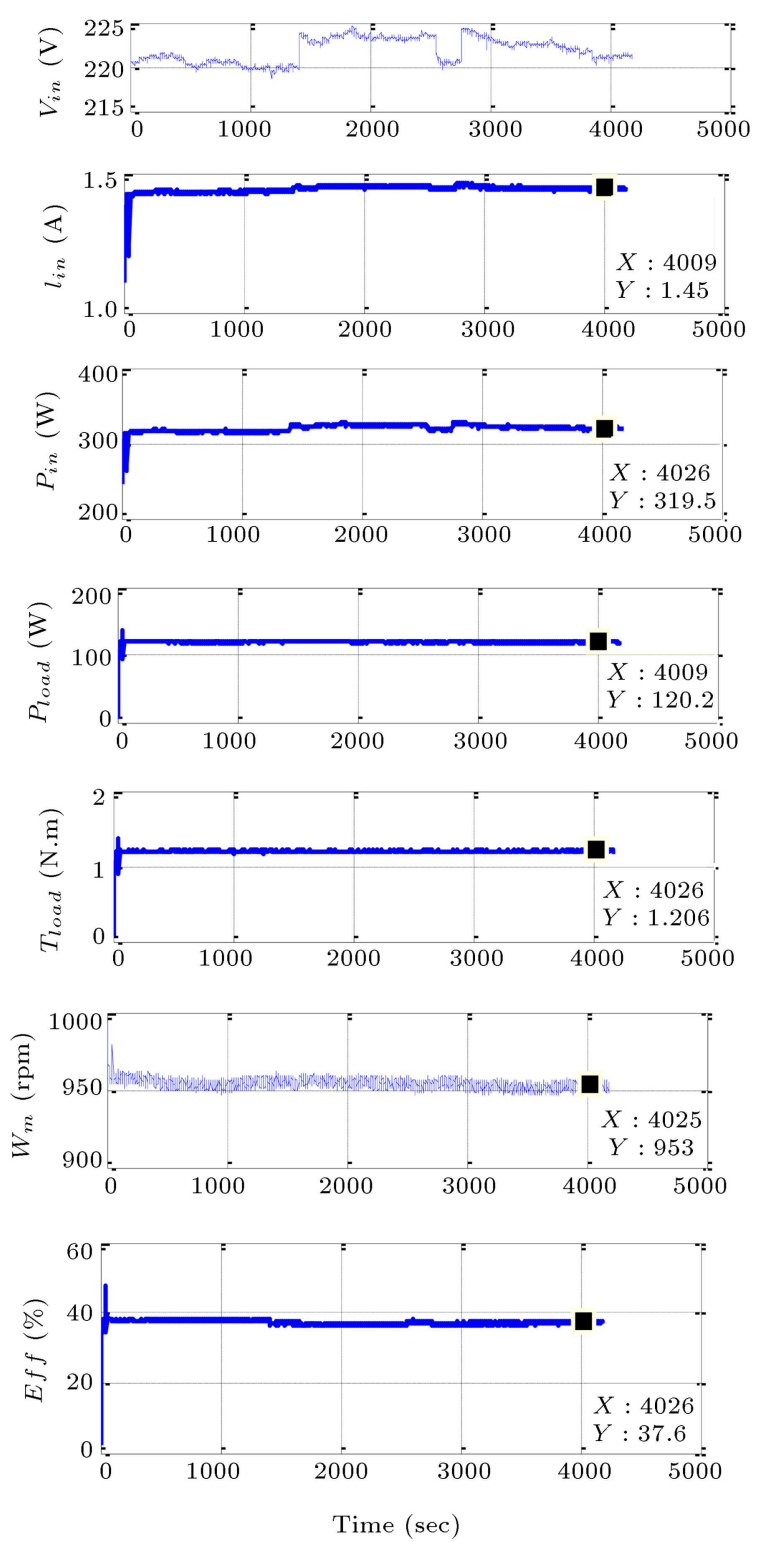

Figure 10. Duty test results of the $1 / 2 \mathrm{hp}$ single-phase induction motor of a 5000 evaporative cooler at a low speed rate of $950 \mathrm{rpm}$ under rated torque of 1.25 N.m.

types in the Iranian market and, also, most of consumers use the coolers at a low speed rate of $950 \mathrm{rpm}$, the replacement of SPIMs with brushless motors leads to the reduction of energy consumption by evaporative coolers to the half.

\subsection{Curve test at a high speed rate of 1450 rpm under variable load torque}

In this test, the applied load torque of the brushless motor at a speed rate of $1450 \mathrm{rpm}$ is changed from zero to slightly more than rated torque. The motor firstly starts up and is working in no-load for one minute. Then, in 40 seconds, the torque increases from zero to 2.7 N.m. Figure 11 shows the results of this test in which the drive input current increases to $1.6 \mathrm{~A}$ 

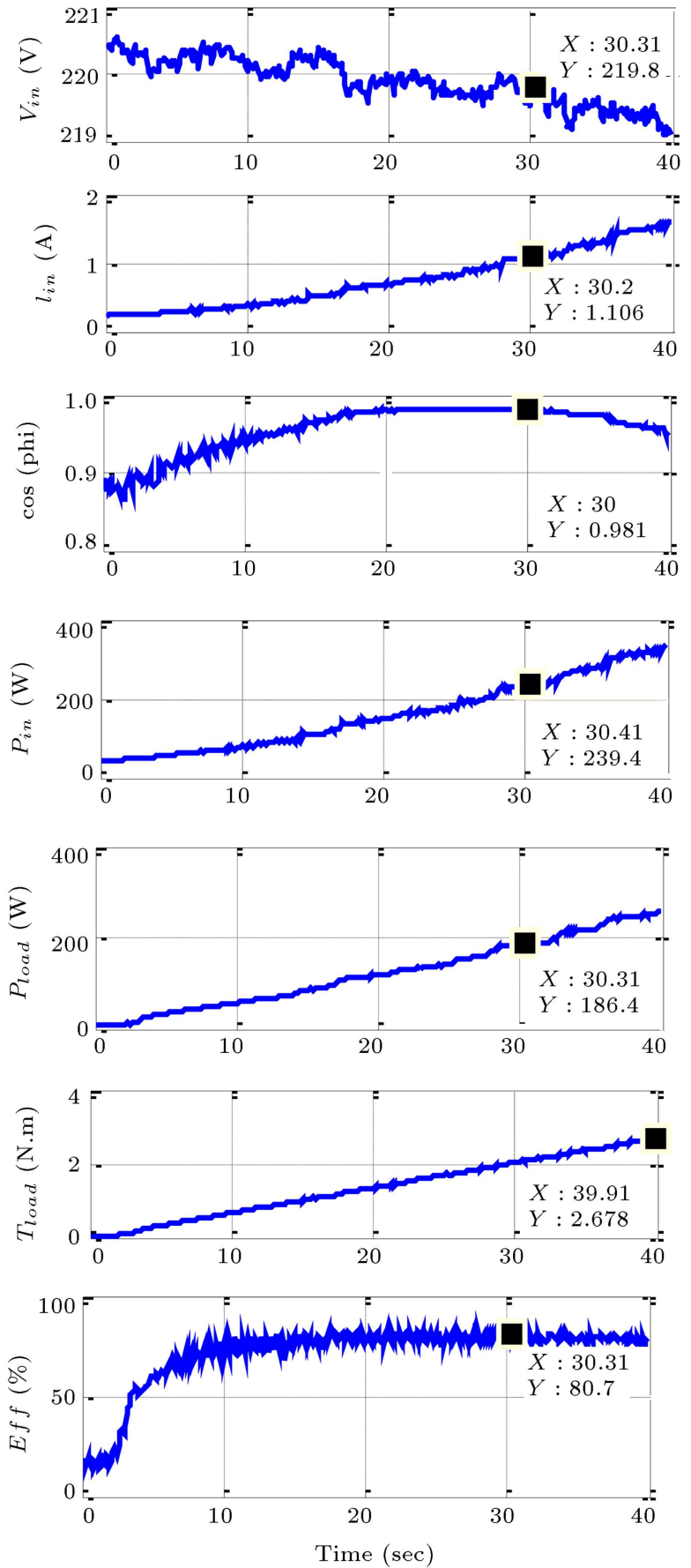

Figure 11. Curve test results of the $1 / 2 \mathrm{hp}$ brushless motor of a 5000 evaporative cooler at a high speed rate of $1450 \mathrm{rpm}$ under variable load torque.

with an increase in the load torque. The input and output power values are also increased by increasing the load; moreover, the power factor is often above 0.9. After $t=10 \mathrm{sec}$, the load torque passes through from 0.4 N.m, and the system efficiency reaches $80 \%$ and higher. In other words, at higher speeds, in a wide range of the load torques, the system's efficiency is significantly higher than the single-phase induction motor's.
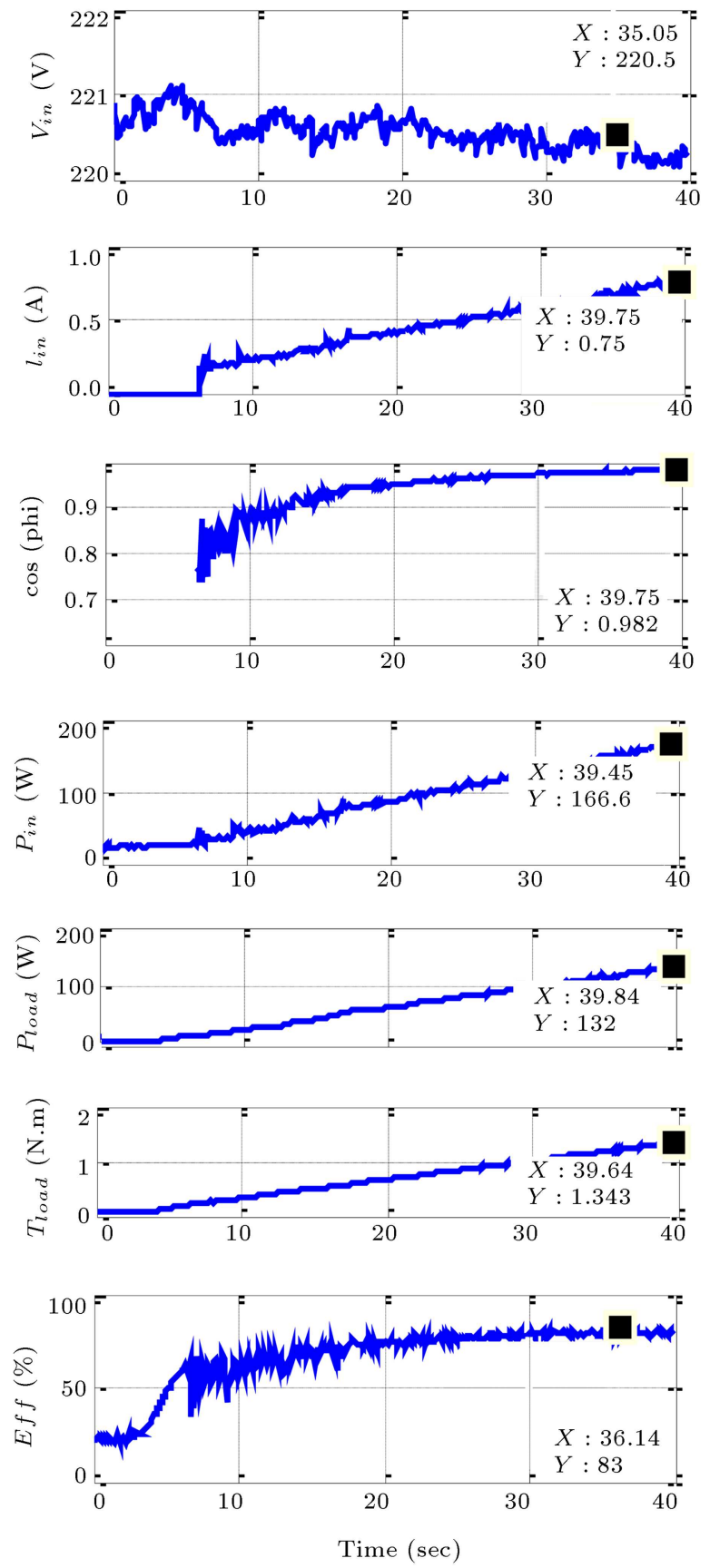

Figure 12. Curve test results of the $1 / 2 \mathrm{hp}$ brushless motor of a 5000 evaporative cooler at a low speed rate of $950 \mathrm{rpm}$ under variable load torque.

\subsection{Curve test at a low speed rate of 950 rpm under variable load torque}

In this test, the applied load torque of the brushless motor at a speed rate of $950 \mathrm{rpm}$ is changed from zero to the load torque of 1.34 N.m. The results of this test are shown in Figure 12. As observed earlier, by increasing the torque, the input current of the drive increases to $0.75 \mathrm{~A}$. After $t=10 \mathrm{sec}$, the load torque and the system efficiency exceed 0.3 N.m and $60 \%$, respectively. 
Table 2. Dynamometer test results of two brushless and single-phase induction motors with rated $1 / 2 \mathrm{hp}$ for an evaporative cooler.

\begin{tabular}{llcccc}
\hline \multirow{2}{*}{ Quantity } & \multicolumn{2}{c}{ Low speed (950 rpm) } & \multicolumn{2}{c}{ High speed (1450 rpm) } \\
\cline { 2 - 5 } & PMBL & SPIM & PMBL & SPIM \\
\hline 1 & Input power (W) & 153 & 320 & 442 & 781 \\
2 & Output power (W) & 124.4 & 120 & 368 & 372 \\
3 & Load torque (N.m) & 1.25 & 1.21 & 2.5 & 2.5 \\
4 & Power factor of drive & 0.98 & - & 0.97 & - \\
5 & Input current of drive (A) & 0.7 & 1.45 & 2.57 & 2.5 \\
6 & THD current of drive (\%) & 8.2 & 0 & 5 & 0 \\
7 & Speed ripple (rpm) & 10 & - & 12 & - \\
8 & Efficiency (\%) & 83 & 37.6 & 84 & 48.3 \\
\hline
\end{tabular}

\subsection{Conclusion on dynamometer test of the brushless motor drive}

To complete the tests according to the standard, the efficiency test is carried out at half of the rated speed under rated torque $2.5 \mathrm{~N} . \mathrm{m}$. The motor efficiency is obtained as $71.7 \%$ that exceeds the standard requirement for this power range, which is $61.9 \%$. The results of the tests performed in this section are summarized in Table 2. The THD values listed in this table are much lower than the permitted THD in the standard and in Table 1. The overall efficiency rates of the brushless motor drive system at both high and low speeds are $83 \%$ and $84 \%$, respectively. They exceed the standard requirement for the brushless motors listed in Table 1 that are $66.3 \%$ and $81.1 \%$, respectively. It should be noted that the achieved efficiency of the brushless motor drive is $60 \sim 100 \%$ higher than the efficiency of SPIMs; therefore, the application of brushless motors results in a significant increase in energy saving.

\section{Airflow test results of the evaporative cooler equipped to brushless}

In order to evaluate the performance of the designed brushless motor under actual load, a 5,000 $\mathrm{m}^{3} / \mathrm{h}$ evaporative cooler equipped to $1 / 2 \mathrm{hp}$ brushless motor is tested by a reference airflow measuring system. This test is carried out based on the ANSI/ASHRAE 1332015 standard, which determines considerations for testing the standard evaporative coolers [19]. In this test, the power consumed by the brushless motor at different airflows is measured. Figure 13 shows the test station in the laboratory.

The airflow rate is determined by measuring the differential pressure $(\Delta P)$ across elliptical flow nozzles in chambers, as shown in Figure 13(a). In the actual use, this $\Delta P$ is due to the length of the air duct used by the consumer. In evaporative coolers equipped with SPIMs, with higher $\Delta P$, the load torque on the motor increases and, then, the motor speed decreases due to slip of the SPIM, resulting in lower airflow. A motor that can produce more airflow with lower power consumption is more suitable. The purpose of this test is to evaluate the performance of a cooler with both brushless motor and SPIM in the actual load and condition.

Airflow measuring test is carried out for two 5000 air conditioners, equipped with SPIM and brushless motor. Figure 14 shows the absorbed power from grid by each motor. As shown, at an airflow rate of $6,000 \mathrm{~m}^{3} / \mathrm{h}$, the brushless motor receives the power of $377 \mathrm{~W}$ from a $220 \mathrm{~V}$ grid, whereas the cooler with SPIM receives $691 \mathrm{~W}$ that is about $83 \%$ more than the brushless motor. In addition, for an airflow rate of $5,000 \mathrm{~m}^{3} / \mathrm{h}$, the power rates of the brushless and SPIM are 300 and $610 \mathrm{~W}$, respectively. For an airflow rate of $3,000 \mathrm{~m}^{3} / \mathrm{h}$, the power rates of these two motors are $180 \mathrm{~W}$ and $500 \mathrm{~W}$, respectively. The comparison of these values shows that the brushless motor in the actual load conditions has a much lower power consumption than a SPIM. It should be noted that most commercial evaporative coolers that are equipped with SPIMs are ranked as E and F in terms of energy labels; however, brushless motors can be easily assigned to $\mathrm{A}^{+}$category.

\section{Aeration improvement of the evaporative cooler based on power control}

The nominal airflow rate of an evaporative cooler is achieved at a certain length of cooler's duct. In the application based on constant speed regulation, increasing the length of the duct decreases the airflow rate from its nominal value, and vice versa. It means that if the length of the duct is smaller, the airflow rate will be greater than the nominal value, which may not be desirable for the customer in both cases. To solve this problem, this paper assumes that if the brushless motor is to be controlled in the power control mode instead of using the speed control mode and operation 


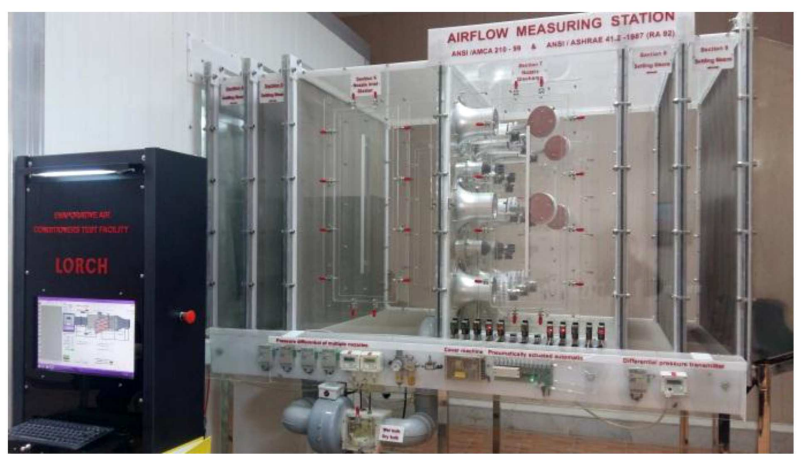

(a)

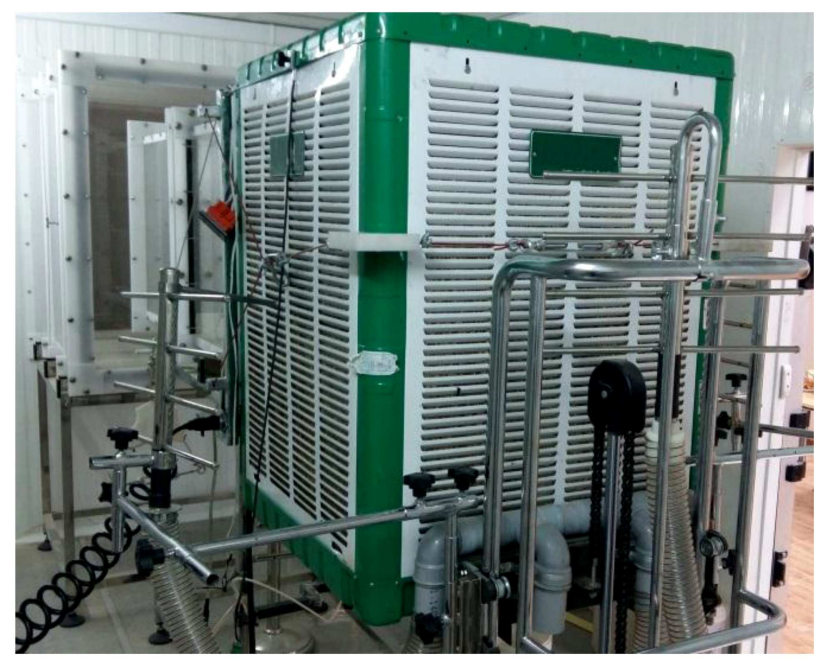

(b)

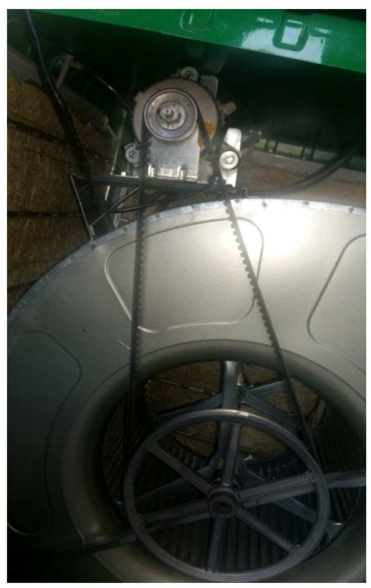

(c)

Figure 13. Airflow test system for the evaporative cooler in the reference laboratory: (a) Airflow measuring station, (b) evaporative cooler equipped with brushless motor at test stand, and (c) brushless motor placed in the evaporative cooler.

at a constant speed, the variations of the airflow rate in different ducts are less than those in the speed control mode. The reason for this behavior of the fan can be described with respect to fan curve $(Q-\Delta P)$ for the given constant power instead of fan curve at a constant

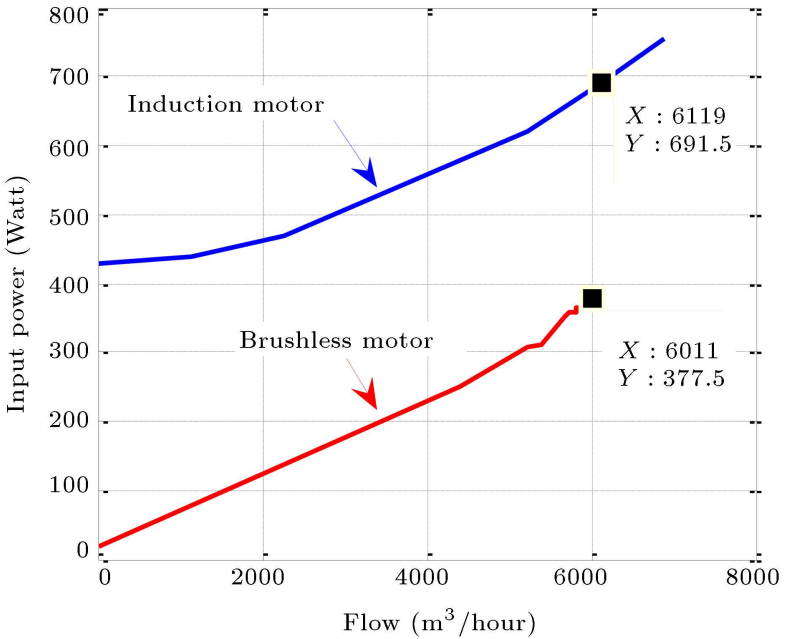

Figure 14. Consumed power versus airflow by brushless and single-phase induction motors installed in the 5000 evaporative cooler.

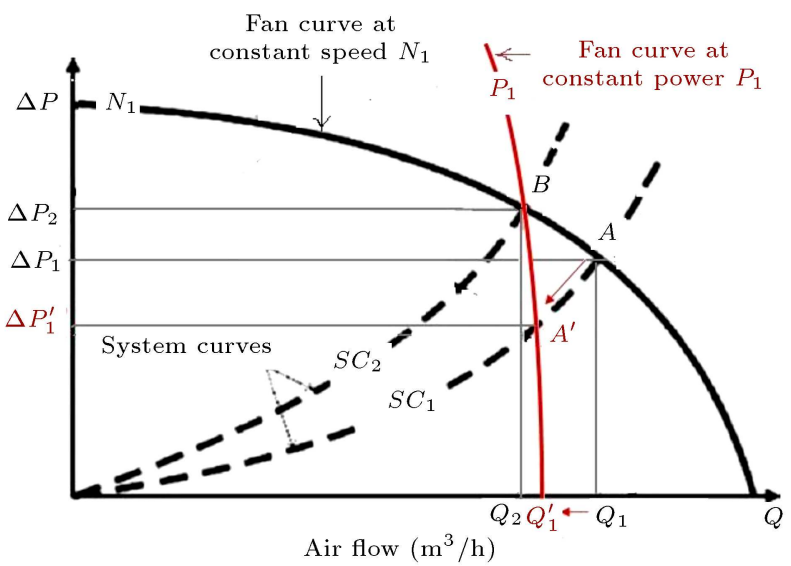

Figure 15. Fan characteristic curves and system resistance curves of a centrifuge fan at a constant speed N1 and constant power P1.

speed. As shown in Figure 15, the red curve shows the fan curve when the input power to the fan is kept constant in value of $P_{1}$. The fan curve in the constant power mode has a much greater slope than that in the constant speed mode. Therefore, for two curves of $S C_{1}$ and $S C_{2}$, the amount of airflow rate will be $Q_{1}^{\prime}$ and $Q_{2}$ and operating point associated with the $S C_{1}$ curve in this case will be point $\mathrm{A}^{\prime}$ instead of point $\mathrm{A}$.

It is clear that the shifting value $\left(Q_{1}-Q_{2}\right)$ associated with the constant speed curve is greater than displacement $\left(Q_{1}^{\prime}-Q_{2}\right)$ associated with the constant power curve. It means that for two ducts with different lengths in the constant power mode, the reduction of the airflow rate is less than one in the constant speed mode. It should be noted that, in the constant power mode, the fan speed associated with $S C_{2}$ (point B) is higher than that associated with $S C_{1}$ (point $\mathrm{A}^{\prime}$ ). It means that, for a duct with higher friction losses, the fan should rotate at higher speeds. The reason for this 


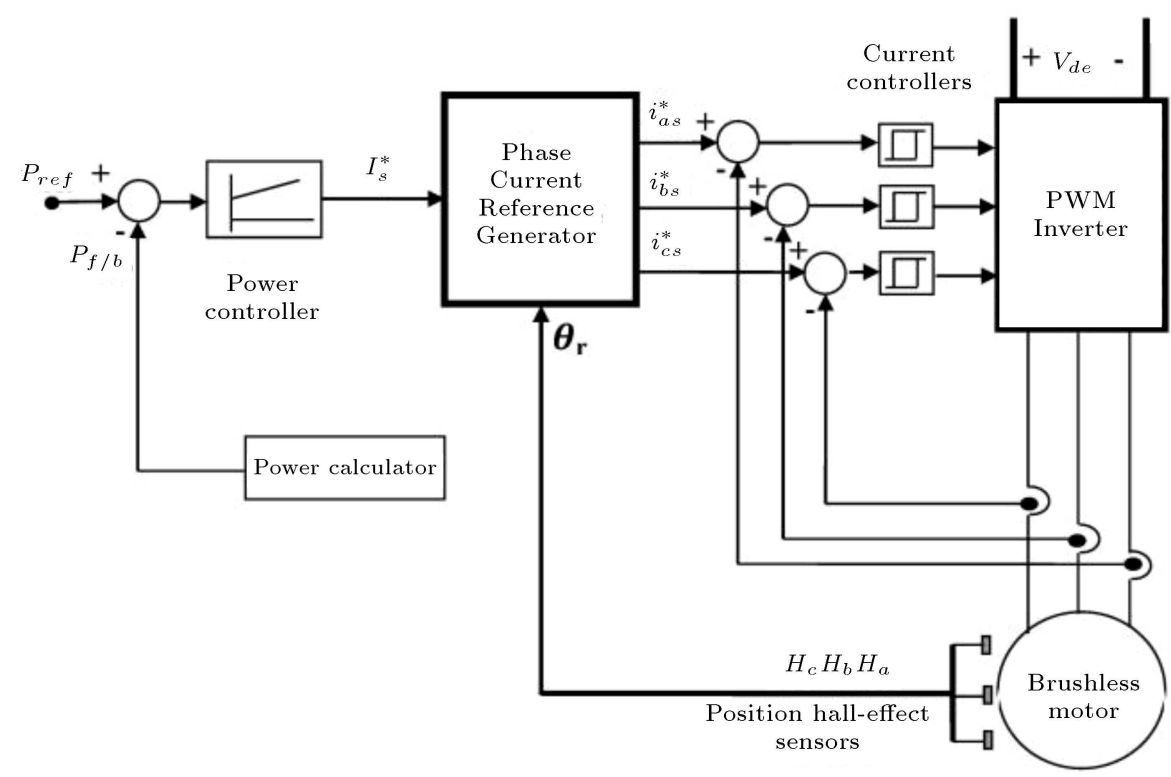

Figure 16. Block diagram of the suggested control system of the brushless motor drive based on the power control approach used for the evaporative cooler.

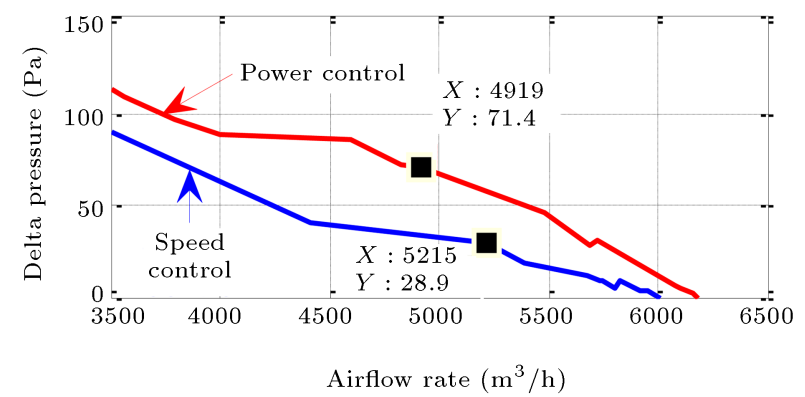

Figure 17. Comparison of airflow test results of constant speed and constant power methods.

phenomenon can be explained by Affinity fluid law and Newton's motion law easily. The block diagram of the brushless motor drive control system is drawn based on the power control approach, as shown in Figure 16. The main difference between the aforementioned block diagram and the block diagram of the conventional brushless motor drive (for coolers) shown in Figure 4 lies only in the outer control loop.

Now, two control methods of constant speed and constant power are applied to the brushless motor installed in a $5,000 \mathrm{~m}^{3} / \mathrm{h}$ evaporative cooler. Figure 17 shows the fan characteristic curves of the evaporative cooler in both methods. As shown, it is possible to produce a given airflow rate at a higher $\Delta P$ in the constant power method. For example, an airflow rate of about $5,000 \mathrm{~m}^{3} / \mathrm{h}$ by the constant speed method is produced at a pressure difference of $\Delta P=30 \mathrm{~Pa}$, whereas it is obtained at $\Delta P=70 \mathrm{~Pa}$ by the constant power method. This means that, with a longer duct, it is still possible to create an arbitrary airflow rate by the power control method.

\section{Economic considerations for using the brushless motor in application of the evaporative water cooler}

In the previous sections, the performance of the brushless motor was tested with a dynamometer system and, also, actual load. It was observed that the brushless motor was preferred to SPIM under many terms and, in view of energy consumption, an improvement rate of at least $60 \%$ was achieved. The key to using this motor is to consider the cost of a brushless motor and its drive and the success in commercial sales. The cost of this new system can be divided into two main parts of the brushless motor and electrical drive.

The motor includes stator core, stator winding, rotor core, permanent magnet poles, shaft, and bearings. Due to design data, the volume of the stator core in the brushless motor is half of the corresponding volume in SPIM. Moreover, the amount of copper conductor used in the brushless motor is approximately $1 / 3$ of the copper used in SPIM. Moreover, in terms of assembling and production remarks, the production of the stator of a brushless motor is much easier than that of SPIM due to the number of slots and winding distribution. Therefore, the cost of the stator of a brushless motor is $50 \%$ less than the corresponding cost in the SPIM. The most significant increase of the cost of a brushless motor is the use of permanent magnet of the rotor. Based on the current price in the market, cost of the permanent magnet is estimated to be about $25 \%$ of motor's price. Other parts of the motor are bearings, and the cost of roller bearings is about $2 \%$ of the overall motor price, which is not so significant. In total, the cost of a brushless motor in mass production 
will be about $75 \%$ of the cost of a SPIM. Moreover, the estimated cost of the drive is almost equivalent to the cost of a brushless motor. Consequently, it can be concluded that the cost of a brushless motor and drive is approximately $150 \%$ of the cost of the SPIMs. This additional price is returned with respect to the energy saving by the motor and, also, is acceptable for the customer due to the mentioned features of using variable speed drive.

Another point about using the brushless motor drive in the cooler application is the potential cost of drive maintenance, which is not available in the case of using SPIM. Proper design and a lifetime test are essential in this issue such that they embolden the manufacturer to guarantee the performance without the need for repair for a few years and low potential costs.

\section{Conclusion}

In this paper, the results of the design, construction, testing, and performance analysis of a brushless motor and its electrical drive were presented for use in a 5000 commercial evaporative cooler. Designs and construction were carried out in accordance with the requirements of the national standard for brushless motors. After performing the routine tests, the designed system was tested in the actual load conditions at the standard laboratory test of the evaporative cooler, and the captured results were compared with the results of the Single-Phase Induction Motor (SPIM). The results indicate that the evaporative cooler equipped with the brushless motor easily received energy grade A, while the SPIM received grade $\mathrm{F}$ or $\mathrm{G}$. To make an analogy of the former coolers with commercial and conventional evaporative coolers equipped with SPIMs, the brushless motor was only tested at high and low speeds that had an efficiency rate of at least $60 \%$ higher than SPIM. However, it is obvious that this extra efficiency is achieved over a wide range of speeds. A brief analysis of the economic considerations and the cost of production was carried out. The additional charge imposed on the customer was found to be about $50 \%$ more than the cost of the SPIM. Technically, the results of this research indicated that the performance of the brushless motor in this application could be improved by adopting more suitable control methods such as current or power control schemes instead of the speed control scheme. In this way, a newly constant power control method was developed instead of the conventional constant speed control method to solve the problem of a reduction in the airflow rate caused by using longer duct in the buildings. Further, by improving the design of the brushless motor and the use of other topologies, such as outer rotor structure, the overall efficiency of the cooler can be increased.
Furthermore, in order to increase the reliability of the drive system and reduce the complexity and cost, the application of sensorless control methods is strongly recommended instead of the low-cost Hall-Effect position sensors.

\section{Acknowledgment}

This article is based on the research project number 26916-96 of the Research Deputy of University of Kashan. The authors are grateful to the Energy Research Center of University of Kashan, Center for the Development of Technology for Advanced Electric Motors of the Power Research Institute, the Electromotor Laboratory of the Iranian National Standards Organization (INSO), and the Evaporative Cooler Test Lab. of the Lorch Company.

\section{References}

1. Sojdei, F., Eslami, M., and Sayfi, N. "Potential of energy conservation in the industry of Iran", ECEEE Industrial Summer Study Proceedings, pp. 323-330 (2014).

2. Sadeghzadeh, S.M., Zare, M., and Akbari, H. "Economic technological assessment of energy consumption optimization in three-phase electromotors in the industry sector", 5th National Energy Conference (in Persian), Tehran, Iran, pp. 1-9 (2005).

3. Caetano, R.G.D., Pontes, M.G.S.R., Costa, V.L.L., Pontes, R.S.T., and Neto, C.C. "Energy efficiency electric motor systems: Motor replacement analysis-A case study", Simposio Brasileiro de Sistemas Eletricos (SBSE), Rio de Janeiro, Brazil, pp. 1-6 (2018).

4. Lee, K., Rugge, R., and Yang, B. "Energy saving HVAC system modeling and closed loop control in industrial and commercial adjustable speed drives", IEEE Energy Conversion Congress and Exposition (ECCE), Pittsburgh, USA, pp. 1286-1292 (2014).

5. Ferreira, F.J.T.E. and Almeida, A.T.D. "Overview on energy saving opportunities in electric motor driven systems - Part 1 system efficiency improvement", IEEE/IAS 52nd Industrial and Commercial Power Systems Technical Conference (I \& CPS), Detroit, USA, pp. 1-8 (2016).

6. Binder, A. "Potentials for energy saving with modern drive technology-a survey", International Symposium on Power Electronics, Electrical Drives, Automation and Motion, Anacapri, Italy, pp. 90-95 (2008).

7. Kerdsup, B. and Kreuawan, S. "Design of synchronous reluctance motors with IE4 energy efficiency standard competitive to BLDC motors used for blowers in air conditioners", IEEE International Electric Machines and Drives Conference (IEMDC), Miami, USA, pp. 16 (2017).

8. Persson, E., Kulatunga, A., and Sundararajan, R. "The challenges of using variable-speed motor drives 
in appliance applications", Electrical Insulation Conference and Electrical Manufacturing Expo, Nashville, USA, pp. 453-458 (2007).

9. Wang, H. and Leng, J. "Summary on development of permanent magnet synchronous motor", Chinese Control and Decision Conference (CCDC), Shenyang, China, pp. 689-693 (2018).

10. Rathikrindi, K.S., Paramasivam, S., and Sandeep, L. "Energy saving opportunities through variable frequency drive for commercial air conditioners", 4th International Conference on Electrical Energy Systems (ICEES), Tamil Nadu, India, pp. 338-340 (2018).

11. Pullaguram, D., Mishra, S., and Banerjee, S. "Standalone BLDC based solar air cooler with MPPT tracking for improved efficiency", IEEE rth Power India International Conference (PIICON), Rajasthan. India, pp. 1-5 (2016).

12. Krishnan, A.A., Ajith, P.R., Ashwin, K., Deepak, S., and Pillai, N.S. "Sensorless operation of brushless DC motor drive designed for air conditioners", International Conference on Innovations in Electrical, Electronics, Instrumentation and Media Technology (ICEEIMT), Coimbatore, India, pp. 71-74 (2017).

13. The Iranian National Standard, Rotating Electrical Machines-Specification and Criteria for Energy Consumption and Energy Labeling Instruction of BLDC Motors, INSO 3772-30-1-3 (2017).

14. Kamalakannan, D., Mariappan, V., and Ramanathan, N. "Energy efficient appliances in a residential building", International Conference on Sustainable Green Buildings and Communities (SGBC), Chennai, India, pp. 1-6 (2016).

15. Dalcalia, A. and Akbaba, M. "Optimum pole arc offset in permanent magnet synchronous generators for obtaining lowest voltage harmonics", Scientia Iranica, Trans. D: Computer Science \& Engineering and Electrical Engineering, 24(6), pp. 3223-3230 (2017).

16. Arehpanah, M. and Kashe, H. "Cogging torque reduction of interior permanent magnet synchronous motor (IPMSM)", Scientia Iranica, Trans. D: Computer Science \& Engineering and Electrical Engineering, 25(3), pp. 1471-1477 (2018).

17. Halvaei Niasar, A., Vahedi, A., and Moghbelli, H. "Low cost sensorless control of four-switch, brushless DC motor drive with direct back EMF detection", Journal of Zhejiang University, Science-A (JZUS), 10(2), pp. 201-208 (2009).
18. Halvaei Niasar, A., Ahmadi, M., and Edjtahed, S.H. "Sensorless control of non-sinusoidal permanent magnet brushless motor using selective torque harmonic elimination control method based on full-order sliding mode observer", Advances in Power Electronics Journal, 2016, Article ID 9358604, pp. 1-13 (2016).

19. ASHRAE, Standard 133-2015 - Method of Testing Direct Evaporative Air Coolers, (ANSI Approved) (2015).

\section{Biographies}

Abolfazl Halvaei Niasar (S'04-M'06-SM'14) was born in Kashan, Iran in 1974. He received his BSc, MSc, and PhD degrees in 1996, 1999, and 2008 from Isfahan University of Technology (IUT), University of Tehran (UT), and Iran University of Science and Technology (IUST), respectively, all in Electrical Engineering. He has joined the Department of Electrical and Computer Engineering at University of Kashan, Kashan, Iran since 2008 as an Assistant Professor. He has authored more than 80 technical papers published in journals and conference proceedings. He is the holder of two Iranian patents and has directed some industrial research projects. His current major research interests include PM and Brushless DC motor (BLDC) drives, sensorless drives, design, analysis and control of electrical machines, development of Electric Vehicles (EVs) and Hybrid Electric Vehicles (HEVs), DSPbased control systems, and industrial control systems engineering. Dr. Halvaei is a senior member of the Institute of Electrical and Electronics Engineers, IEEE.

Hossein Nik Khah was born in Kashan, Iran in 1993. He received the BSc degree from University of Kashan, Kashan, Iran in 2014 in Electrical Engineering. He is currently an MSc student at University of Kashan. His research interests are BLDC motor drives and power electronics.

Fariborz Eshrat Abadi was born in Neyshabour, Iran in 1967. He received the BSc degree from University of Ferdowsi, Mashhad, Iran in 1992 in Mechanical Engineering. He has been teaching for four years as an instructor in Machine Dynamics and Vibration Laboratory and has been designing and constructing CNC machines for 19 years. He is currently with Arman Energy Company as the Director Manager in Toos industrial town in Mashhad, Iran in the field of designing and manufacturing the evaporative water coolers equipped with permanent magnet brushless motors. 